\title{
Survival Analysis of Time to Retest for HIV Among Men Who Have Sex with Men from Metro Manila, Philippines: A Single-Center Prospective Study
}

https://doi.org/10.37719/jhcs.2020.v2i2.oa003

\author{
SAMUEL BRANDO H. PIAMONTE, MA ${ }^{1}$ \\ https://orcid.org/0000-0001-6234-9476
}

JHOANNE C. YNION, MSc, MM²

https://orcid.org/0000-0001-9521-4850

\section{University of the Philippines Los Baños, Laguna, Philippines \\ 2International Rice Research Institute, Laguna, Philippines \\ Corresponding author's email: shpiamonte@up.edu.ph}

\section{Abstract}

Background: Regular HIV testing means early detection of the virus and prompt access to treatment. However, factors affecting retesting following receipt of a non-reactive test result are not yet well understood. This study aims to determine the predictors of time to repeat HIV testing among men who have sex with men (MSM) from Metro Manila, Philippines within six months following receipt of a non-reactive test result.

Methods: A prospective study was implemented at a community-based HIV testing and counseling center. A total of 250 non-reactive MSM from Metro Manila and with a recent risk of acquiring HIV were the respondents. At baseline, data on socio-demographic factors were gathered; while at followup, repeat test status of each participant within six months after baseline was collected.

Results: Two retests per 1,000 person-weeks were recorded. Mean survival time was 23.93 weeks, 95\% Cl: [23.18 - 24.68]. Cox proportional hazards regression demonstrated that statistically significant factors of time to retest were age $(\mathrm{HR}=0.90,95 \% \mathrm{Cl}[0.85,0.96])$ and number of tests in lifetime $(\mathrm{HR}=1.12,95 \% \mathrm{Cl}[1.06,1.18])$.

Conclusion: Although the average time to return is within the recommended period of three to six months, the low return rate suggests the call for encouraging repeat HIV testing among MSM with non-reactive results and recent risk of acquiring HIV. Repeat testing has been shown to be facilitated by age and previous testing history. HIVIAIDS counselors and program administrators can aim for MSM who are older and with relatively low testing history to help meet the global target of ending the 
HIVIAIDS global epidemic.

Keywords: HIV, retesting, men who have sex with men, prospective study, survival analysis

\section{Introduction}

$\mathrm{T}$ he 90-90-90 target of the Joint United Nations Programme on HIV and AIDS (UNAIDS) calls on countries that by $2020,90 \%$ of persons living with HIV (PLHIV) must have known their status, $90 \%$ of those diagnosed must have undergone antiretroviral therapy (ART); and $90 \%$ of those undergoing ART must have reached viral suppression (UNAIDS, 2014). Achieving these targets have been projected to eliminate the global AIDS epidemic by 2030.

Based on the 90-90-90 target, HIV testing is suggested to be the initial step to achieve the elimination of the epidemic. At the individual level, evidence suggests that early HIV detection and prompt treatment is likely to increase the life expectancy (Dilernia et al., 2010) and mitigate mortality (Davis et al., 2013). This is because PLHIV can have undetectable and have untransmittable viral load after consistent treatment, thereby making their risk of sexually infecting others negligible (UNAIDS, 2018). Meanwhile, at the community level, identification of cases can help illuminate disease prevalence (Tenny \& Hoffman, 2020). These benefits implicate the importance of having timely and routine testing for HIV among those who are at risk of acquiring HIV infection because, through repeat tests, one can early identify his or her status. From a programmatic perspective, understanding repeat tests are important because it can shed light on the efficacy of testing and counseling strategies (Puljić et al., 2014).

Literature is suggesting that there is an HIV epidemic among Filipino men who have sex with men (MSM) (Ross, et al., 2015; Gohil et al., 2020). The World Health Organization (2010) recommended those with indeterminate status, those who have a previous and ongoing risk of acquiring HIV, and key populations including MSM to undergo repeat voluntary counseling and testing (VCT) as repeat testing for HIV is not recommended for the general population. In addition, the US Centers for Disease Control and Prevention (2018) suggested that sexually active gay or bisexual men may benefit from a more frequent HIV testing specifically every three to six months.

Foreign literature about predictors significantly related to HIV testing is vast. Studies have seen the significant relationship of HIV testing with socio-demographic variables such as age, socioeconomic status, education, geographic distance, and marital status. On the other hand, there were studies that highlighted behavioral factors such as HIV testing history and engagement in unprotected sex.

Also, knowledge of repeat testing is limited (Harichund et al., 2019); and local studies about it have not yet been conducted. Investigating retesting behavior among at risk groups will guide health 
administrators and decision makers for VCT interventions. In the Philippines, the Department of Health (DOH, 2019) reported that the majority of the new HIV infections are through male to male contact; and in terms of distribution, the new cases tend to come from Metro Manila. Thus, this study sought to shed light on repeat VCT for HIV among Metro Manila-based MSM who tested non-reactive for HIV antibodies. Particularly, this study aims to identify the factors related with time to repeat test following receipt of a negative HIV test result in order to identify groups who can be targeted in the promotion of timely and regular testing.

\section{Methods}

\section{Research Design}

A prospective study was conducted at a community-based HIV testing and counseling center in Mandaluyong City, Philippines.

\section{Research respondents}

MSM from Metro Manila, Philippines were the focus of the study since new cases of HIV infections are skewed against this population and the said region. MSM who attended the HIV testing and treatment facility for VCT and received a non-reactive test result were recruited to participate. HIVIAIDS counselors invited their MSM clients who received a non-reactive HIV test result to participate in the research after post-test counseling. The method of asking MSM who receive nonreactive HIV test results might be prone to selection bias; thus, the counselors were offered a script for standard communication with clients. Once expressed interest, the principal investigator came inside the counseling room, explained further the details of the research, and provided screening of participants to determine eligibility for study participation.

In terms of eligibility, the client must be 1) biologically male who is sexually experienced with other men, 2) at least 18 years of age, 3) studying, working, or residing in Metro Manila, 4) willing to provide contact information for the follow-up data gathering, and 5) engaged in any of the following for the past twelve months - a) unprotected sex, b) multiple anal sex partners, c) multiple oral sex partners, d) sex under the influence of alcohol, e) sex under the influence of drugs, or f) trading money for sex (i.e. bought or sold sex). MSM who were part of other projects in the study site requiring regular follow-up tests were excluded because they will automatically have a retest record. MSM who were anticipating leaving the National Capital Region (NCR) were also excluded. This will also help minimize the bias of changing location with the subsequent test. Invitation and screening stopped when the target sample size had been achieved. Sample size (n) was calculated using the formula:

$$
n=\left(\frac{Z_{\frac{\alpha}{2}}}{B}\right)^{2} p(1-p)
$$


The target sample size was achieved with a 7\% margin of error (B) and $95 \%$ confidence level. Since no local studies have been identified to examine retesting rates, the study used $50 \%$ as proportion ( $p$ ) in order to minimize bias and to generate the maximum sample size yielding $196(n)$. However, due to anticipated attrition among recruited participants, it was increased by $25 \%$ (i.e. 46 ), having a final sample size of 250 .

\section{Data and method}

A pre-tested questionnaire in English was administered to the eligible clients for selfadministration. Monthly income was asked directly in the pre-test; however, as many participants skipped it, it was transformed into a categorical variable in the final questionnaire to increase the item response rate.

At baseline, the self-administered questionnaire containing questions about sociodemographic characteristics, testing history, and preferred mode of communication for follow-up was given to the research respondents. Data on engagement in unprotected sex was unearthed from the screening questionnaire. Participants were instructed that if they will repeat their test in the study site within six months, a drop box will be available containing envelopes, each containing a follow-up questionnaire.

A drop box was also placed at the other branch of the testing center in Pasay City since clients might get a repeat test at this branch. For security, no identifying questions were asked in the follow-up questionnaire; and the drop boxes were checked regularly by the respective point person of the research in each site. To link the repeaters with their baseline questionnaire, their Unique Identification Code, a set of letters and numbers unique to the participant, was asked in the follow-up questionnaire. The follow-up questionnaire inquired about the branch they were having the retest as well as the date of the repeat test. After six months following the baseline test, participants who had no records of repeat tests in the clinics were contacted and asked if they had a repeat test elsewhere. Records of the two study sites were also checked for data validation.

The dependent variable was time-to-retest. Number of weeks from initial test to retest was computed, with non-repeaters having 28 weeks (i.e. maximum duration of study participation of six months plus one week allowance) as time value. In terms of status, a participant was coded "1" if he returned within 28 weeks after baseline VCT, otherwise, "0". Participants who were lost to follow-up were right-censored and were coded "0" too. Since the recruited MSM are not part of any HIV-related projects requiring regular testing, it is assumed that all returns for another test are under one's volition.

The variables that were included in this study were informed by a literature review of predictors of HIV testing. Continuous predictors were age in years and number of tests in lifetime (including the VCT on the date of recruitment). Binary categorical predictors were relationship status (in an any form relationship or not) and engagement in unprotected anal sex for past twelve months 
(yes or no). Multi-category variables include education (elementary level/graduate, high school level/graduate, college level/graduate, post-graduate level/graduate, or technical/vocational), sexual orientation (exclusively or more attracted to the opposite sex which was coded heterosexual, equally attracted to both sexes which was coded bisexual, or exclusively or more attracted to the same sex which was coded homosexual), and monthly income (less than 10,000 Pesos, 10,001 to 20,000, 20,001 to $30,000,30,001$ to $40,000,40,001$ to 50,000 , and above 50,000). Present address was also asked directly but was categorized into District $1,2,3$, or 4 , or outside NCR (for those who work or study in NCR but residence is outside of it).

\section{Data analysis}

R 3.6.2 (R Core Team, 2019) was used to perform analyses of data. Descriptive statistics were computed first to provide a profile of the participants. To determine if distribution of percentages in follow-up significantly depart from baseline, Chi-Square Goodness of Fit test was performed.

A Kaplan-Meier curve was performed to illustrate and estimate the average time to retest in weeks. A Kaplan Meier curve shows the probability of an event (i.e., the time to retest) at a certain time interval. On the other hand, a Cox proportional hazards regression model was generated to determine factors of time to retest. A Cox proportional hazards regression analysis is a survival analysis that measures the probability of respondents suffering the event of interest, given that the participant has survived up to a specific time. This analysis utilized the package for survival analysis in $\mathrm{R}$ (Therneau, 2015). Education was dropped in the regression analysis due to low variability in frequency distribution. Since MSM who had anticipated change in residence were excluded, location was not treated as time-dependent covariate. The study used a $5 \%$ level of significance.

\section{Ethical clearance}

Prior to data gathering, a technical and ethics review was obtained from the University of the Philippines Manila Research Ethics Board (Code: 2018-021-01). All participants received full information about the study and was issued an informed consent form which would indicate voluntary participation when signed. All data were treated with utmost confidentiality and participants were kept anonymous. The study adhered with the Philippines' Data Privacy Act of 2012.

\section{Results}

Table 1 presents the percentage distribution of the socio-demographic characteristics of the recruited respondents. 
Table 1. Profile of Respondents

\begin{tabular}{|c|c|c|c|c|c|}
\hline \multirow[b]{2}{*}{ Variable } & \multicolumn{2}{|c|}{$\begin{array}{l}\text { Baseline } \\
(n=250)\end{array}$} & \multicolumn{2}{|c|}{$\begin{array}{c}\text { Follow-up } \\
(\mathrm{n}=209)\end{array}$} & \multirow[t]{2}{*}{ p-value } \\
\hline & frequency & $\%$ & frequency & $\%$ & \\
\hline Age (in years) & & & & & .94 \\
\hline 18 to 22 & 61 & 24.40 & 52 & 24.88 & \\
\hline 23 to 26 & 94 & 37.60 & 80 & 38.28 & \\
\hline \multirow[t]{2}{*}{ More than 26} & 95 & 38.00 & 77 & 36.84 & \\
\hline & \multicolumn{2}{|c|}{$\bar{x}=26(S D=4.39)$} & \multicolumn{2}{|c|}{$\bar{x}=26(S D=4.19)$} & \\
\hline Testing history & & & & & .82 \\
\hline 1 to 2 & 128 & 51.20 & 103 & 49.28 & \\
\hline 3 to 4 & 57 & 22.80 & 51 & 24.40 & \\
\hline \multirow[t]{2}{*}{ More than 4} & 65 & 26.00 & 55 & 26.32 & \\
\hline & \multicolumn{2}{|c|}{$\bar{x}=4(S D=3.30)$} & \multicolumn{2}{|c|}{$\bar{x}=4(S D=3.32)$} & \\
\hline Monthly Income (in PhP) & & & & & .99 \\
\hline$<10,000$ & 32 & 12.80 & 26 & 12.44 & \\
\hline 10,001 to 20,000 & 65 & 26.00 & 53 & 25.36 & \\
\hline 20,001 to 30,000 & 77 & 30.80 & 69 & 33.01 & \\
\hline 30,001 to 40,000 & 37 & 14.80 & 30 & 14.35 & \\
\hline 40,001 to 50,000 & 15 & 6.00 & 13 & 6.22 & \\
\hline$>50,000$ & 24 & 9.60 & 18 & 8.61 & \\
\hline Educational Attainmenta & & & & & .88 \\
\hline Elementary level/graduate & 1 & 0.40 & 1 & 0.48 & \\
\hline High school level/graduate & 6 & 2.40 & 3 & 1.44 & \\
\hline College level/graduate & 224 & 89.60 & 190 & 90.91 & \\
\hline Post-graduate level/graduate & 14 & 5.60 & 11 & 5.26 & \\
\hline Technical/vocational & 5 & 2.00 & 4 & 1.91 & \\
\hline Present Address & & & & & .97 \\
\hline Outside NCR & 20 & 8.00 & 18 & 8.61 & \\
\hline District 1 (Capital) & 18 & 7.20 & 16 & 7.66 & \\
\hline District 2 (East) & 129 & 51.60 & 104 & 49.76 & \\
\hline District 3 (North) & 17 & 6.80 & 16 & 7.66 & \\
\hline District 4 (South) & 66 & 26.40 & 55 & 26.32 & \\
\hline Relationship status & & & & & .29 \\
\hline Single & 206 & 82.40 & 178 & 85.17 & \\
\hline In an any form of relationship & 44 & 17.60 & 31 & 14.83 & \\
\hline Sexual orientation & & & & & .61 \\
\hline Heterosexual & 13 & 5.20 & 8 & 3.83 & \\
\hline Bisexual & 80 & 32.00 & 65 & 31.10 & \\
\hline Homosexual & 157 & 62.80 & 136 & 65.07 & \\
\hline Condomless anal sex for the past 12 months & & & & & .50 \\
\hline Yes & 168 & 67.20 & 145 & 69.38 & \\
\hline No & 82 & 32.80 & 64 & 30.62 & \\
\hline
\end{tabular}

a Elementary and high school levels were combined in the analysis since there was a detected violation of assumption in the original categories. 
At baseline, mean age of the participants was 26 years $(S D=4.39)$. Typically, monthly income falls between 20,001 to 30,000 (31\%) which was slightly followed by the 10,001 to 20,000 income range (26\%). Almost all of the participants had at least college level education where about $90 \%$ has entered college while $6 \%$ has reached postgraduate level. Slightly more than half of the participants (52\%) came from the Eastern district of NCR while about a few $(8 \%)$ reside outside Metro Manila. Eight out of $10(82 \%)$ were single; and most of the participants were exclusively or more attracted with the same sex $(63 \%)$. More than half of them had unprotected anal sex for the past twelve months (67\%). Finally, the average number of HIV tests conducted in lifetime was four (SD = 3.30).

It might appear that the distribution of participants is skewed in some categories; however, the recruited participants had similar characteristics with the Metro Manila MSM and transgender respondents of the 2015 Integrated HIV Behavioral \& Serologic Surveillance (DOH, 2015) in terms of age, relationship status, and engagement in unprotected anal sex. In terms of location, the distribution of the participants' current addresses reflect the 2015 census (Philippine Statistics Authority, 2016) that the Eastern district is the most populous in the region. Characteristics of participants who remained at follow-up did not significantly depart from baseline profile $(p>.05)$. Figure 1 and Table 2 shows the survival times gathered from respondents.

\section{Kaplan-Meier survival estimate}

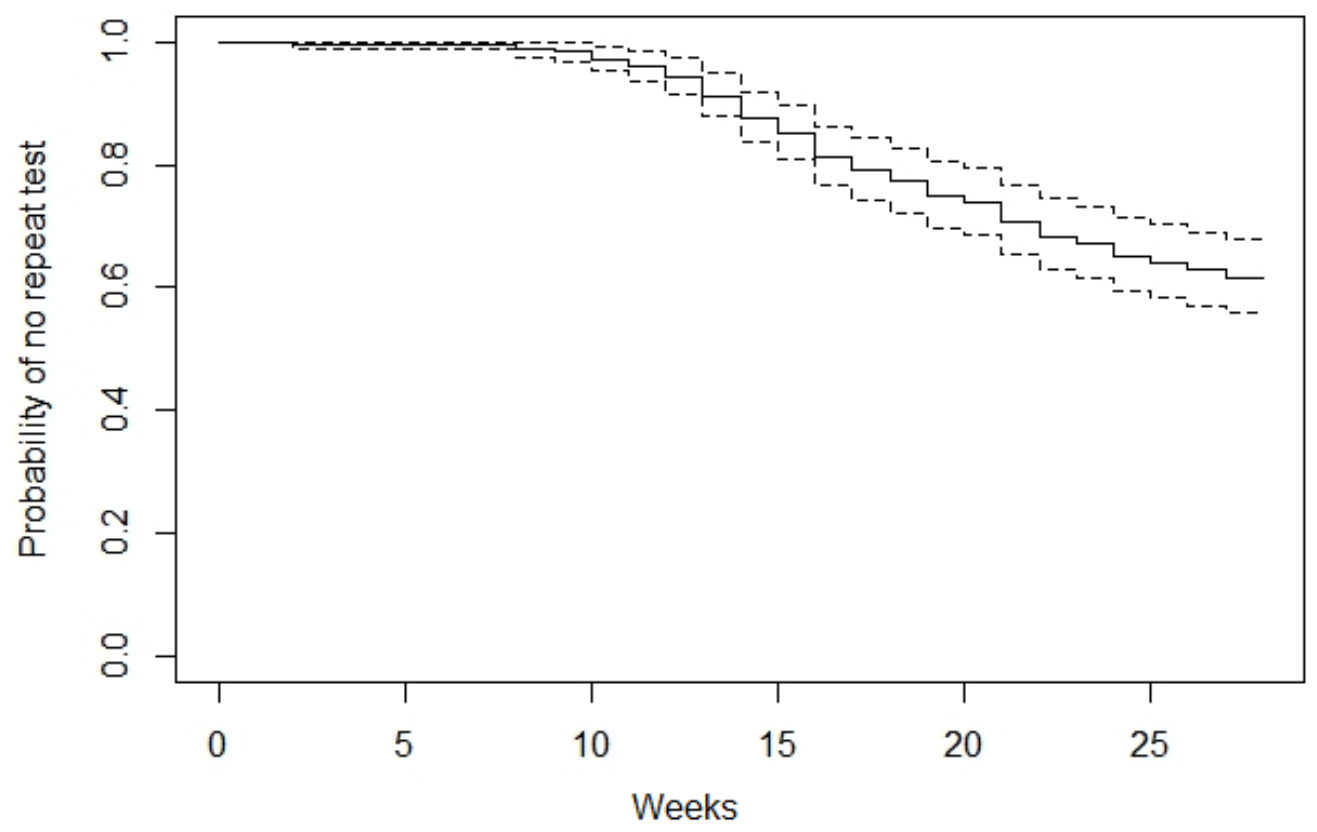

Figure 1. Kaplan-Meier curve of participants with no repeat tests 
Table 2. Kaplan-Meier estimates of participants who did not take HIV repeat test

\begin{tabular}{|c|c|c|c|c|c|c|}
\hline \multirow{2}{*}{$\begin{array}{c}\text { Time } t_{i} \\
\text { (weeks) }\end{array}$} & \multirow{2}{*}{$\begin{array}{l}\text { Number of } \\
\text { remaining } \\
\text { participants }\end{array}$} & \multirow{2}{*}{$\begin{array}{l}\text { Number of } \\
\text { clients who } \\
\text { took a retest }\end{array}$} & \multicolumn{4}{|c|}{ Kaplan-Meier estimator } \\
\hline & & & $\mathbf{S}\left(\mathrm{t}_{\mathrm{i}}\right)$ & SE & LL & UL \\
\hline 2 & 250 & 1 & 1.00 & 0.00 & 0.99 & 1.00 \\
\hline 8 & 249 & 2 & 0.99 & 0.01 & 0.98 & 1.00 \\
\hline 9 & 247 & 1 & 0.98 & 0.01 & 0.97 & 1.00 \\
\hline 10 & 246 & 3 & 0.97 & 0.01 & 0.95 & 0.99 \\
\hline 11 & 243 & 3 & 0.96 & 0.01 & 0.94 & 0.99 \\
\hline 12 & 240 & 4 & 0.94 & 0.01 & 0.92 & 0.97 \\
\hline 13 & 236 & 8 & 0.91 & 0.02 & 0.88 & 0.95 \\
\hline 14 & 228 & 9 & 0.88 & 0.02 & 0.84 & 0.92 \\
\hline 15 & 219 & 6 & 0.85 & 0.02 & 0.81 & 0.90 \\
\hline 16 & 213 & 10 & 0.81 & 0.02 & 0.77 & 0.86 \\
\hline 17 & 203 & 5 & 0.79 & 0.03 & 0.74 & 0.84 \\
\hline 18 & 198 & 5 & 0.77 & 0.03 & 0.72 & 0.83 \\
\hline 19 & 193 & 6 & 0.75 & 0.03 & 0.70 & 0.80 \\
\hline 20 & 187 & 2 & 0.74 & 0.03 & 0.69 & 0.80 \\
\hline 21 & 185 & 8 & 0.71 & 0.03 & 0.65 & 0.77 \\
\hline 22 & 177 & 6 & 0.68 & 0.03 & 0.63 & 0.74 \\
\hline 23 & 171 & 3 & 0.67 & 0.03 & 0.62 & 0.73 \\
\hline 24 & 168 & 5 & 0.65 & 0.03 & 0.60 & 0.71 \\
\hline 25 & 163 & 3 & 0.64 & 0.03 & 0.58 & 0.70 \\
\hline 26 & 160 & 3 & 0.63 & 0.03 & 0.57 & 0.69 \\
\hline 27 & 157 & 3 & 0.62 & 0.03 & 0.56 & 0.68 \\
\hline
\end{tabular}

From the 250 participants, 96 participants were known to undergo a repeat VCT for HIV within the study duration. Between baseline and follow-up, 96 retests out of 5,982 person-weeks or two repeat tests per 1,000 person-weeks were recorded. Forty-one participants were not reachable and were lost to follow-up. This MSM along with those who did not undergo a repeat test and were lost to follow up were right-censored.

More repeat tests were initiated somewhere 12 weeks after baseline tests. The median survival time cannot be calculated since less than $50 \%$ of the participants were observed to repeat a test; however, on average, survival time was 23.93 weeks, $95 \% \mathrm{Cl}$ : [23.18 - 24.68]. The Kaplan-Meier curve also shows the participant's probability of not taking a repeat test during the 28-week period. With respect to repeat testing after three to six months, data reveal that the probability that a client will not take a repeat test in at least 12 weeks (three months) is about $90 \%$; while in at least 24 months (six months), the probability decreases to about $60 \%$. Table 3 presents the computed Cox regression coefficients. 
Table 3. Cox regression coefficients predicting time to retest $(n=250)$

\begin{tabular}{|c|c|c|c|c|c|}
\hline \multirow{2}{*}{ Variable } & \multirow{2}{*}{$\begin{array}{c}\text { Hazard } \\
\text { ratio }\end{array}$} & \multirow{2}{*}{$\begin{array}{l}\text { Std. } \\
\text { Error }\end{array}$} & \multicolumn{2}{|c|}{$95 \% \mathrm{Cl}$} & \multirow{2}{*}{ p-value } \\
\hline & & & LL & UL & \\
\hline Age & 0.90 & 0.03 & 0.84 & 0.96 & $<0.01$ \\
\hline Testing history & 1.12 & 0.03 & 1.06 & 1.18 & $<0.01$ \\
\hline Income $<10,000$ & \multicolumn{5}{|c|}{ Referent } \\
\hline Income 10,001 to 20,000 & 1.00 & 0.38 & 0.48 & 2.10 & .99 \\
\hline Income 20,001 to 30,000 & 1.82 & 0.37 & 0.88 & 3.77 & .11 \\
\hline Income 30,001 to 40,000 & 1.30 & 0.46 & 0.53 & 3.18 & .57 \\
\hline Income $>40,001$ to $50,000^{a}$ & 1.48 & 0.46 & 0.60 & 3.63 & .40 \\
\hline Present address outside NCR & \multicolumn{5}{|c|}{ Referent } \\
\hline Present address District 1 (Capital) & 0.77 & 0.55 & 0.26 & 2.28 & .64 \\
\hline Present address District 2 (East) & 0.90 & 0.39 & 0.42 & 1.94 & .79 \\
\hline Present address District 3 (North) & 0.87 & 0.52 & 0.31 & 2.41 & .78 \\
\hline Present address District 4 (South) & 0.69 & 0.43 & 0.30 & 1.59 & .38 \\
\hline Relationship status (Single) & \multicolumn{5}{|c|}{ Referent } \\
\hline Relationship status (In a relationship) & 0.66 & 0.31 & 0.36 & 1.21 & .18 \\
\hline Sexual orientation (Heterosexual) & \multicolumn{5}{|c|}{ Referent } \\
\hline Sexual orientation (Bisexual) & 1.36 & 0.62 & 0.40 & 4.60 & .62 \\
\hline Sexual orientation (Homosexual) & 1.68 & 0.61 & 0.51 & 5.58 & .39 \\
\hline Condomless anal sex (No) & \multicolumn{5}{|c|}{ Referent } \\
\hline Condomless anal sex (Yes) & 0.98 & 0.24 & 0.61 & 1.56 & .93 \\
\hline
\end{tabular}

Out of all the tested predictor variables, only age and testing history were revealed to be statistically significant. Controlling for other variables, the probability of repeat test falls by $10 \%$ for every additional year of participant's age, on the average ( $\mathrm{HR}=0.90,95 \% \mathrm{Cl}[0.84,0.96])$. Conversely, it was seen that as testing history increases, the hazard increases by 1.12 times at any point in time $(\mathrm{HR}=1.12,95 \% \mathrm{Cl}[1.06,1.18])$.

\section{Discussion}

The Philippines is facing an alarming rate of HIV incidence (Gangcuangco et al., 2013). According to the DOH (2019), in September 2019 alone, there were 1,038 newly confirmed persons living with HIV. Ninety-five percent of whom were men. Mean age was 28 years old and half of the cases belong to the 25 to 31 age cohort. The most predominant mode of transmission was sexual contact $(97 \%)$ and among the new cases, more than half (59\%) was reported to be via male to male 
transmission.

HIV testing is considered a method of preventing further infections since individuals who know their HIV-positive status can have the virus sexually untransmittable once they have undergone management of viral load. Routine and timely testing is important because linkage to care becomes early once the virus has been detected.

In this study, age has been found to be a significant variable. Studies differ in terms of the relationship of age with HIV testing. Some indicate that older individuals are more likely to get tested than younger ones (Andrews, 2011; Conserve et al., 2013; Peltzer \& Matseke, 2013; den Daas et al., 2016). However, an opposite relationship was provided by De Allegri et al. (2015) where individuals aged 20-24 years were more likely to get tested relative to other age groups. Similarly, Norman \& Gebre (2005) reported in their study that the youth were more likely to report past HIV testing. In this study, retesting falls as age increases. This corroborates the study of Duffus et al. (2009) that older adults are more likely to be late testers. One possible explanation for this result is that the one provided by Brown et al. (2018) in their study where they stated that there is a belief among older adults that they were not at risk of acquiring HIV; thus, they were less likely to be willing to get tested for HIV. The conflicting result of this study with other studies that found age to be significant also can be attributed to how age was handled in the study. In the present paper, it was treated as a continuous variable rather than categorical to avoid loss of power (Frøslie et al., 2010).

In this study, testing history also significantly predicts time to retest. Burchell et al. (2003) in their study on inmates revealed that testing while incarcerated in the past year was independently associated with previous HIV testing. This can be explained by frequency of behavioral performance being able to account for variance in later performance (Ajzen, 2002). Much empirical evidence has supported past behavior as a determinant of future behavior and the strong relationship between the two corroborates temporal stability of the particular behavior and its antecedents (Ajzen, 2011).

The study has identified age and testing history as significant predictors of time to retest. Other variables did not emerge as significant predictors which can be explained by the fact that the other studies which found the insignificant predictors as significant had different social, political, economic, and cultural contexts. Evidence suggests that HIVIAIDS counselors and administrators can target MSM who are older and those with relatively low testing history for routine testing. Although this study cannot point what particular message can be delivered as this beyond the scope of this research, there are available tools that can be used for counseling; but these should be translated in terms of the situation of the client for cultural appropriateness. As WHO (2015) puts it, counselors must provide messages that are responsive and tailored to the situation of the clients.

This study is not one without limitations, and it is best to understand the conclusion while taking precautions of the study limitations. First, the focus of this paper revolves around sociodemographic and a few behavioral variables. It does not provide information on the role of 
psychological factors towards repeat testing. The use of factors beyond demographic variables as test variables is suggested for future studies. Second, the effect of changing one's location might have affected retesting status. Data on change on residence were not retrieved at follow-up; however, to eliminate potential bias, MSM who had anticipated change in location was screened out. Future similar studies can take into consideration change of residence because one might have retested because of becoming nearer or farther to a testing facility after location change. The reasons for repeating the test or not is beyond this current research. MSM who did not return for a repeat test might have engaged in protective behaviors and might have perceived that a repeat test is no longer necessary. Therefore, our recommendations are anchored on the assumption that the recruited participants are in an ongoing risk and future research can explore this limitation. Finally, the respondents were MSM from Metro Manila who were recruited at a single site only. Results may not be true to other key populations like injection drug users and other MSM from other regions. Results can only be applicable to Metro Manila MSM with non-reactive HIV test results and with recent risky sexual behavior. Multi-center studies are suggested to strengthen external validity. Having more gathered information, larger sample sizes are also recommended because such can unearth significant relationships if these indeed exist (Thiese et al., 2016).

\section{Conclusion}

The low rate of repeat tests among MSM suggests strengthening promotion of routine and timely testing among MSM. HIVIAIDS counselors being the first line of individuals testers face upon learning of tests results should promote messages that target MSM who are older and those with relatively low testing history to promote regular and timely testing.

\section{Conflict of Interest}

The authors have no conflict of interest to declare

\section{Acknowledgment}

This paper would not be possible without the UPLB Gender Center for the funding and and Love Yourself, Inc. for providing logistical support.

\section{Funding}

The University of the Philippines Los Baños (UPLB) Gender Center provided funding for the research. 


\section{Author Contribution}

Samuel Brando H. Piamonte: Conceptualized the paper, collected the data and wrote the paper. Jhoanne C. Ynion: Performed the analysis, assisted in writing the paper

\section{References}

Andrews, B. E. (2011). Prevalence and correlates of HIV testing among Caribbean youth. International Journal of STD \& AIDS, 22(12): 722-726. https://doi.org/10.1258/ijsa.2011.011088.

Ajzen, I. (2002). Residual Effects of Past on Later Behavior: Habituation and Reasoned Action Perspectives. Personality and Social Psychology Review, 6(2), 107-122.

Ajzen, I. (2011). The theory of planned behaviour: Reactions and reflections. Psychology \& Health, 26, 1,1131,127. https://doi.org/10.1080/08870446.2011.613995

Brown, B., Marg, L., LeComte-Hinely, J., Brinkman, D., Zhang, Z., \& Sullivan, G. (2018). Indicators of selfreported human immunodeficiency virus risk and differences in willingness to get tested by age and ethnicity: An observational study. Medicine (Baltimore), 97(31), e11690. https://doi.org/10.1097/MD.0000000000011690.

Burchell, A. N., Calzavara, L. M., Myers T., Schlossberg, J., Millson, M., Escobar, M., Walace, E., \& Major C. (2003). Voluntary HIV testing among inmates: sociodemographic, behavioral risk, and attitudinal correlates. Journal of Acquired Immune Deficiency Syndromes 32(5), 534-41.

Centers for Disease Control and Prevention. (2018). HIV testing 101. Division of HIVIAIDS Prevention. https://www.cdc.gov/hiv/pdf/library/factsheets/hiv-testing-101-info-sheet.pdf

Conserve, D., Sevilla, L., Mbwambo, J. \& King, G. (2013). Determinants of Prevoius HIV Testing and Knowledge of Partner's HIV Status Among Men Attending a Voluntary Counseling and Testing Clinic in Dar es Salaam, Tanzania. American Journal of Men's Heath, 7(6), 450-460. https://doi.org/10.1177/1557988312468146.

Davis, D. H. J., Smith, R., Brown, A., Rice, B., Yin, Z., Delpech, V. (2013). Early diagnosis and treatment of HIV infection: magnitude of benefit on short-term mortality is greatest in older adults. Age and Ageing, 42(4), 520-526. https://doi.org/10.1093/ageing/aft052

De Allegri, M., Agier, I., Tiendrebeogo, J., Louis, V.R., Yé, M., Mueller, O., \& Sarker, M. (2015). Factors Affecting the Uptake of HIV Testing among Men: A Mixed Method Study in Rural Burkina Faso. PLoS one, 10(7), 2-15. https://doi.org/10.1371/journal.pone.0130216.

den Daas, C.. Doppen, M., Martine, S., \& de Coul, E. (2016). Determinants of Never Having Tested For HIV Among MSM in the Netherlands. BMJ Open, 6(1), e009480. http://dx.doi.org/10.1136/bmjopen-2015009480.

Department of Health (DOH). (2015). 2015 Integrated HIV Behavioral and Serologic Surveillance. Manila: Department of Health Epidemiology Bureau.

Department of Health (DOH). (2019). HIVIAIDS \& ART Registry of the Philippines. Manila: Department of Health Epidemiology Bureau.

Dilernia D. A., Mónaco, D. C., Krolewiecki, A., César, C., Cahn, P., Salomón H. (2010). The importance of early diagnosis for the survival of HIV positive patients. Medicina (B Aires), 70(5), 453-6. 
Duffus, W.A., Weis, K., Kettinger, L., Stephens, T., Albrecht, H., Gibson, J.J. (2009). Risk-based HIV testing in South Carolina health care settings failed to identify the majority of infected individuals. AIDS Patient Care STDS, 23(5), 339-45. https://doi.org/10.1089/apc.2008.0193.

Frøslie, K. F., Røislien, J., Laake, P., Henriksen, T., Qvigstad, E., \& Veierød, M. B. (2010). Categorisation of continuous exposure variables revisited. A response to the Hyperglycaemia and Adverse Pregnancy Outcome (HAPO) Study. BMC Medical Research Methodology, 10:103. doi: 10.1186/1471-2288-10103.

Gangcuangco, L. M., Tan, M. L., \& Berba, R. P. (2013). Prevalence and risk factors for HIV infection among men having sex with men in Metro Manila, Philippines. Southeast Asian Journal of Tropical Medicine and Public Health, 44(5), 810-7.

Gohil, J., Baja, E. S., Sy, T. R., Guevara, E. G., Hemingway, C., Medina, P. M. B., Coppens, L., Dalmacion, G. V., \& Taegtmeyer, M. (2020). Is the Philippines ready for HIV self-testing?. BMC Public Health, 20, 34. https://doi.org/10.1186/s12889-019-8063-8.

Harichund, C., Kunene, P., Simelane, S., Karim, Q. A., \& Moshabela, M. (2019). Repeat HIV testing practices in the era of HIV self-testing among adults in KwaZulu-Natal, South Africa. PLoS One, 14(2), e0212343. https://doi.org/10.1371/journal.pone.0212343.

Joint United Nations Programme on HIVIAIDS (UNAIDS). (2014). 90-90-90 An ambitious treatment target to help end the AIDS epidemic. https://www.unaids.org/sites/default/files/media_asset/90-90-90_en.pdf Joint United Nations Programme on HIVIAIDS. (2018). Undetectable = Untransmittable: Public Health and HIV Viral Load Suppression. https://www.unaids.org/sites/default/files/media_asset/undetectableuntransmittable_en.pdf

Norman, L. R. \& Gebre, Y. (2005). Prevalence and correlates of HIV testing: an analysis of university students in Jamaica. Medscape General Medicine, 7(1), 70.

Peltzer, K. and Matseke, G. (2013). Determinants of HIV testing among young people aged 18-24 years in South Africa. African Health Sciences, 13(2), 1012-1020. https://doi.org/10.4314/ahs.v13i4.22.

Philippine Statistics Authority. (2016). Population of the National Capital Region (Based on the 2015 Census of Population). https://psa.gov.ph/content/population-national-capital-region-based-2015-censuspopulation-0.

Puljić, V. M., Ličina, M. L. K., Kavić, M., \& Blažić, T. N. (2014) Repeat HIV Testing at Voluntary Testing and Counseling Centers in Croatia: Successful HIV Prevention or Failure to Modify Risk Behaviors? PLoS ONE, 9(4), e93734. https://doi.org/10.1371/journal.pone.0093734

R Core Team (2019). R: A language and environment for statistical computing. R Foundation for Statistical Computing, Vienna, Austria. https://www.R-project.org/.

Ross, A., Ditangco, R., Belimac, J., Olveda, R., Mercado, E., Chau, T. \& Crowe, S. (2015). The Dire Sexual Health Crisis Among MSM in the Philippines: an Exploding HIV Epidemic in the Absence of Essential Health Services. International Journal of Infectious Diseases, 37, 6-8. https://doi.org/10.1016/j.jijd.2015.06.001.

Tenny S. \& Hoffman M. R. (2020). Prevalence. In: StatPearls [Internet]. Treasure Island (FL): StatPearls Publishing. https://www.ncbi.nlm.nih.gov/books/NBK430867/.

Therneau, T. (2015). A Package for Survival Analysis in R. R version 2.38. https://CRAN.Rproject.org/package=survival.

Thiese, M. S., Ronna, B., \& Ott, U. (2016). P value interpretations and considerations. Journal of Thoracic Disease, 8(9): E928-E931. https://doi.org/10.21037/jtd.2016.08.16

World Health Organization. (2010). Delivering HIV test results and messages for re- testing and counselling in adults. https://apps.who.int/iris/bitstream/handle/10665/44278/9789241599115_eng.pdf 
World Health Organization. (2015). Consolidated guidelines on HIV testing services: 5Cs: Consent, Confidentiality, Counselling, Correct Results and Connection. https://apps.who.int/iris/bitstream/ handle/10665/179870/9789241508926_eng.pdf

\section{About the Authors}

Samuel Brando H. Piamonte, MA, obtained his BA Sociology and MA Sociology (minor in Applied Nutrition) from the University of the Philippines Los Baños (UPLB) in 2013 and 2019, respectively. He worked for projects involving HIVIAIDS at the World Health Organization Philippines and Research Institute for Tropical Medicine; and substance use at UPLB and Addictus Research and Intervention Center, Inc.. By the time this article was published, he was involved in health research management and health policy at the Philippine Council for Health Research and Development of the Department of Science and Technology. He has presented various papers in local and international conferences and has published studies involving human sexuality, rabies, food and nutrition, and HIVIAIDS.

Jhoanne C. Ynion, MSc, MM, obtained her BSc and MSc in Statistics, and MM in Business Management at the University of the Philippines Los Baños (UPLB) in 2005, 2011, and 2020, respectively. She later joined UPLB as an Instructor and was later promoted as an Assistant Professor. She also worked as a University Researcher at the National Institutes of Health, in UP Manila. After a year, she joined the Market Analysis Research Team at the International Rice Research Institute (IRRI). During her stay at IRRI, she has been involved in several research projects that focused on rice value chain analysis, consumer preferences, and food diets in several countries in South and Southeast Asia. 